\title{
Behavior of RC Beams with Openings Strengthened with CFRP Laminates
}

\author{
Ghada Gamal Ahmed* and Venees Faied Gerges \\ Department of Construction Engineering, Egyptian Russian University ERU, Egypt \\ *Corresponding Author: civilghada@hotmail.com
}

\begin{abstract}
Creating a new opening in the shear zone of casted reinforced concrete beams is one of the critical issues during construction due to building safety and cost impact. Moreover, coordination process is a difficult stage that always lead to major impact on project schedule. To investigate the problem of rectangular openings in beams, all beams are studied as simple beams subjected to eight equidistant concentrated loads. Third large scale beam specimens with different opening location will be presented in this research. The author presents an analytical study on the behavior of RC beams with openings strengthened with CFRP laminates, in order to predict their behavior before and after strengthening. The opening location, cross section shape (rectangular - L-section), number of CFRP layers and compressive strength of concrete are the main parameters that are considered in this research. The current study is carried out using Finite Element Method on software package (ANSYS 15.0). Verification models are simulated at first and compared with similar beams tested experimentally in previous research in order to validate their results, then the parameters mentioned above are analytically studied. The maximum capacity for each beam is obtained after loading them up to failure, then the corresponding displacements are recorded. Moreover, Modes of failure, crack patterns and the relationship between loads and displacements are obtained. Furthermore, the author studies the suitable way to reach the cheapest technical solution in case the opening will be required during design stage or it will be created after casting stage.
\end{abstract}

Keywords: Reinforced concrete beams; Openings; Strengthening; CFRP.

\section{Introduction}

Transverse openings are often provided through beams to accommodate utility ducts and pipes to benefit from the unused space above the beam soffit. It is obvious that such openings are potential source of weakness in the beams. When the service systems are preplanned and the sizes and locations of required openings achieving the necessary layout of pipes and ducts are decided upon well in advance, adequate strength and serviceability may be ensured during the design stage. This, however, is not always the case. There are at least two circumstances that necessitate drilling of holes in an existing structure. The first is in a recently constructed building, when laying the service ducts, the M\&E contractor frequently comes up with the request to drill an opening for the sake of simplifying the arrangement of pipes not carefully considered during the design stage. When such a request comes, the structural designer finds 
that it is difficult to make a decision.

The second circumstance arises in an old building. Where, the openings are created by removing concrete cores for structural assessment of the building. In such a case, however, the holes are generally filled in by non-shrink grout. If the structure is to remain, then the question is whether such a repair is adequate to restore the original level of safety and serviceability of the structure.

The strengthening of reinforced concrete members by externally bonded steel plates or fiberreinforced polymer (FRP) laminates has been used exclusively in recent years due to their costeffectiveness and versatility. Both retrofitting methods of bonding steel plates and bonding FRP externally offer several advantages: 1 ) being inexpensively and rapidly applicable in the field with little or no disturbance; 2) keeping the original configuration of the structure; and 3) maintaining the overhead clearance. Recently, external bonding of FRP laminates became a viable alternative to bonding steel plates for strengthening concrete structures due to its high strength-to-weight ratio, light weight, resistance to chemicals, good fatigue strength, and nonmagnetic property [1 to 4]. The previous experimental studies carried out on behaviour of beams with opening and FRP laminates around openings. However, this study carried out the analysis model study of fifteen simply support reinforced concrete beams to study the behaviour of beam with openings in different locations for rectangular and L-sections. Moreover, strengthening around openings with carbon fibre reinforced polymer (CFRP) and different concrete compressive strength were applied to study opening behaviour.

\section{Objective}

The main objective of this research is to illustrate the main parameters that may have a major impact in the analysis result during the selection of opening location through concrete beam. The investigation considered many parameters which could avoid any miscalculation or additional cost through design stage and after casting. The utilized models of this study are simulated on the ANSYS 15.0 software and verified. The efficiency of such confinement is found by evaluating the result of the analysis with the previous experimental studies. The main parametric study in this research are:

- Opening location through beam.

- Strengthening by CFRP including different layers.

- Different cross section of beam (Rectangular and L-section)

- Concrete compressive strength

\section{Description of the previous tested beams}

There are many researchers studied the opening issue through beam element before and after casting. The previous experimental study by [5\&6] used fifteen one third scale reinforced concrete beams were prepared. All tested beams have the same total length of $2000 \mathrm{~mm}$ and overall cross section of 100x200 mm, as shown in Fig. 1. 


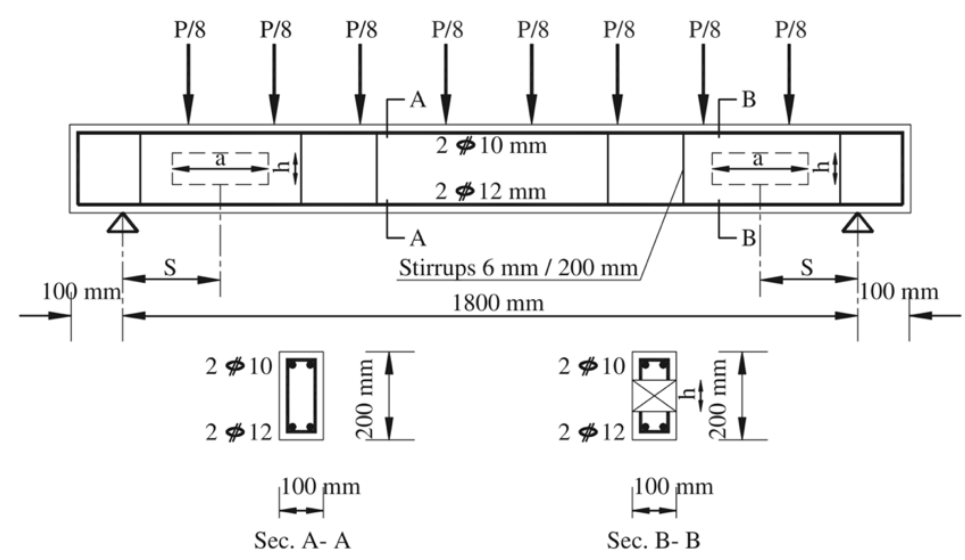

Fig. 1 Loads and steel reinforcement

They were simply support at span of $1800 \mathrm{~mm}$ apart. The steel reinforcement of all beams was: two bars $12 \mathrm{~mm}$ diameter as tension reinforcement; two bars $10 \mathrm{~mm}$ diameter as compression reinforcement and stirrups $6 \mathrm{~mm}$ diameter with $200 \mathrm{~mm}$ spacing. The first beam " $\mathrm{B}$ " was a solid beam without openings and was considered as a reference beam. Every one of the other beams was provided with two openings of $200 \mathrm{~mm}$ length, and $100 \mathrm{~mm}$ height. All the test beams were subjected to eight points loading to closely simulate uniform loading.

\section{Table 1. Details of specimens}

\begin{tabular}{|c|c|c|c|c|}
\hline $\begin{array}{l}\text { Control } \\
\text { beams }\end{array}$ & $\begin{array}{l}\text { Without opening } \\
\text { Without opening L } \\
\text { sec. } \\
\text { With opening } \\
\text { With opening and } \\
\text { CFRP }\end{array}$ & $\begin{array}{l}\text { B } \\
\text { BL } \\
\text { B7 } \\
\text { B1 }\end{array}$ & & \\
\hline \multicolumn{2}{|c|}{$\begin{array}{l}\text { Opening } \\
\text { location } \\
(L=\text { clear } \\
\text { span } / 2=900 \mathrm{~mm})\end{array}$} & BR1 & $\begin{array}{l}2 \mathrm{~L} / 3 \\
\mathrm{BR} 2\end{array}$ & BR3 \\
\hline \multicolumn{2}{|c|}{ CFRP layers } & $\begin{array}{c}\text { Without } \\
\text { BR1 }\end{array}$ & $\begin{array}{c}\text { One } \\
\text { layer } \\
\text { BR1F1 } \\
\end{array}$ & $\begin{array}{c}\text { Two } \\
\text { layers } \\
\text { BR1F2 }\end{array}$ \\
\hline \multicolumn{2}{|c|}{$\begin{array}{l}\text { L section with opening without } \\
\text { CFRP }\end{array}$} & $\begin{array}{l}\text { L/3 } \\
\text { BL1 }\end{array}$ & $\begin{array}{l}2 \mathrm{~L} / 3 \\
\text { BL2 }\end{array}$ & $\begin{array}{c}\mathrm{L} \\
\text { BL3 }\end{array}$ \\
\hline \multicolumn{2}{|c|}{$\begin{array}{l}\text { Concrete } \\
\text { compressive } \\
\text { strength }\left(\mathrm{F}_{\mathrm{cu}}\right) \\
\mathrm{MPa}\end{array}$} & BR1 & BR1C35 & BR1C45 \\
\hline
\end{tabular}

Three control beams only were used from the above-mentioned study. Moreover, the shape of beam cross section was studied in many previous research [7 to 12]. Consequently, twelve beams with different opening location, beam cross section shape, CFRP strengthening and compressive strength are studied by authors, as shown in Table 1. 


\section{Modeling and element types}

The finite element program is utilized in our study using Finite Element Method on software package (ANSYS 15.0). The experimented specimens are modelled and tested in the same procedures as they are tested. The concrete material is modelled using element SOLID 65. The element is defined by eight nodes having three degrees of freedom at each node: translations in the nodal $\mathrm{x}, \mathrm{y}$, and $\mathrm{z}$ directions. The solid is capable of cracking in tension and crushing in compression. The FRP material is modelled using SOLID185 Layered Solid, see Fig. 2. In addition, the reinforcement bars are modelled using element link180. The element is defined by eight nodes having three degrees of freedom at each node: translations in the nodal $\mathrm{x}, \mathrm{y}$, and $\mathrm{z}$ directions. The layered composite specifications including layer thickness, material, orientation, and number of integration points through the thickness of the layer are specified via shell element. Fig. 3 shows the geometry and reinforcement model for the used beams.

The numerical analysis was carried out on fifteen reinforced concrete beams of 1800 mm clear span between supports, four of these beams are used as control beams, two of them are calculated without any opening for rectangular and L section. Other two control beams are investigated with opening dimensions a $\mathrm{x}$ h equal $200 \times 100 \mathrm{~mm}$ created at distances L/3, 2L/3 and $\mathrm{L}$ from centreline of the opening to the edge support as shown in Fig. 4.

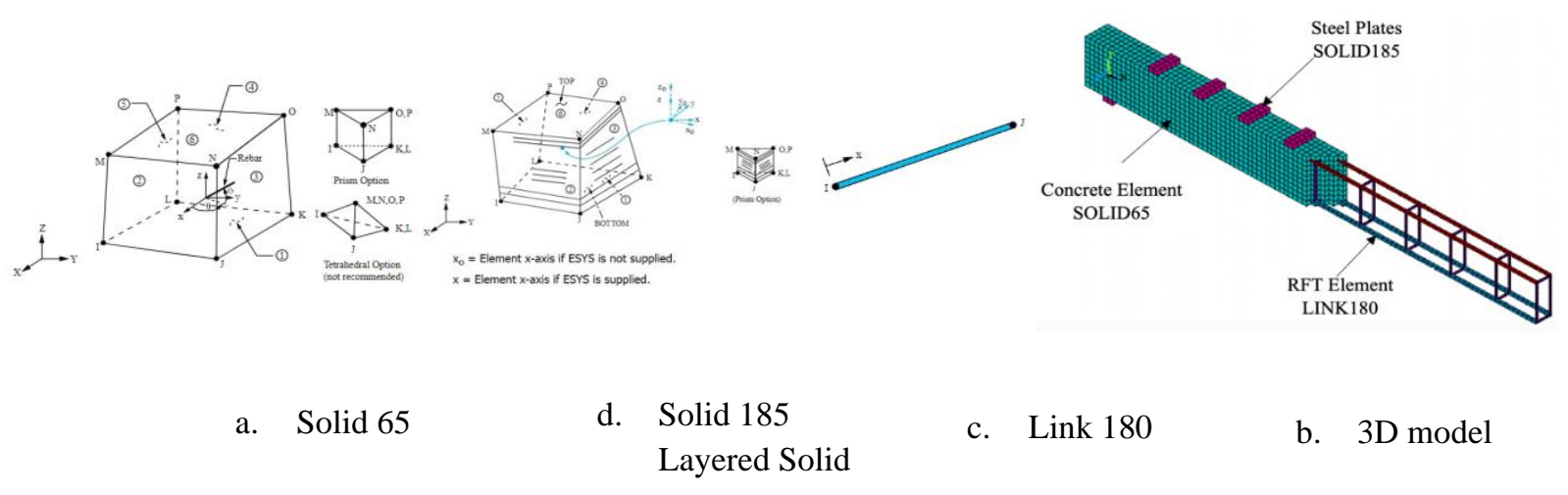

Fig. 2 Geometry and node locations for element types

\section{Result and discussion}

The finite element analysis of the model in this study examines first cracking, yielding of the steel and failure strength of the beam. The nonlinear response is computed by the NewtonRaphson method of analysis. Loading was incrementally increased up to failure. The finite element analysis predictions including the displacement and failure loads are summarized in Table 2. Three experimental beams done by previous experimental study [5] are used as controls beams and compared the accuracy of numerical analysis. 
Table 2. Result of finite element model

\begin{tabular}{ccccc}
\hline Beam no. & \multicolumn{2}{c}{ Failure load (KN) } & \multicolumn{2}{c}{ Displacement (mm) } \\
\cline { 2 - 5 } & Experimentally & Theoretically & Experimentally & Theoretically \\
\hline B & 86.00 & 86.00 & 9.55 & 10.58 \\
B7 & 47.50 & 45.00 & 7.83 & 7.023 \\
B1 & 66.00 & 66.00 & 9.27 & 10.19 \\
\hline BL & 116.6 & & 15.80 \\
\hline BR1 & 74.44 & 10.31 \\
\hline BR2 & 79.4 & 10.71 \\
\hline BR3 & 80.94 & 18.61 \\
\hline BR1F1 & 103.90 & 15.54 \\
\hline BR1F2 & 113.10 & 16.94 \\
\hline BL1 & 91.25 & & 14.47 \\
\hline BL2 & 108.1 & 15.93 \\
\hline BL3 & 111.25 & 11.30 \\
\hline BR1C25 & 74.44 & & 10.31 \\
\hline BR1C35 & 87.80 & & 12.08 \\
\hline BR1C45 & 91.25 & 32.63 \\
\hline
\end{tabular}

\section{Cracking patterns:}

Fig. 5 shows cracking patterns for beams with and without opening. First cracks in beams with opening L/3 appear diagonally at the outer lower corner of the opening (corner 1). Then, other diagonal cracks appear in upper inner corner (corner 3). While, for beams with opening $2 \mathrm{~L} / 3$ and L cracks appear through shear zone more than around opening as shown in Fig. 6. Crack pattern in these beams showed max propagation of cracks near the support and slightly less than amount at the vertex in comparison with the control beam without opening which showed the maximum crack propagation occurred at the vertex.

\section{Model observation:}

From deformation shapes shown in Fig. 6, all beams with opening deflected in the same way around opening with logical slope deflection manner. The slop in the opening side of beam BR1 is formed in the opposite direction. This observation is decreases with the increase of the distance between the opening and support. Moreover, the location of point loads has a major impact related the deformation shape for the solid part above opening location.

\section{Load Deflection Relationship:}

The results of load deflection are presented in Table 2; it can be noticed that the measured deflection of all beams with opening at same load level is almost bigger than that of the control beams without opening. There are some beams have different value due to different opening location and shape of beam section. Moreover, strengthening with CFRP around opening has an improvement in load deflection values. This means that the strengthening process helped the beams to regain part (not all) of its stiffness which was lost by the creation of the openings. 
The amount of stiffness-regain depends on the number of layers of strengthening material has insignificant improvement.

\section{Failure Shear Strength:}

In this analysis, the load-deflection curve for all beams is linearly elastic up to around $20 \%$ of the maximum failure load. Overhead this point, the load increases gradually up and reaches the nonlinearity zone to the maximum load capacity as shown in Fig. 6. Experimental and ANSYS results have almost the same failure result for beams B, B7 and B1. Opening locational and shape of beam section have a major impact on failure load.

Increasing in the compressive strength to $45 \mathrm{MPa}$ of the beam BR1C45 led to increasing in the failure load about $23 \%$ in comparison with beam BR1C25 and the behavior of beams seems a significant improvement of ductility and high energy absorption as shown in Fig. 6. Changing of compressive strength did not affected the crack pattern propagation and shear stress distribution.

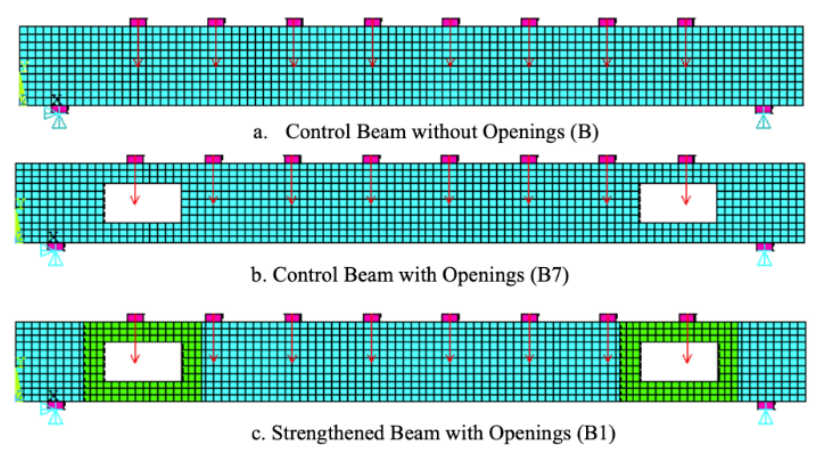

Fig. 3 Geometry Boundary Conditions
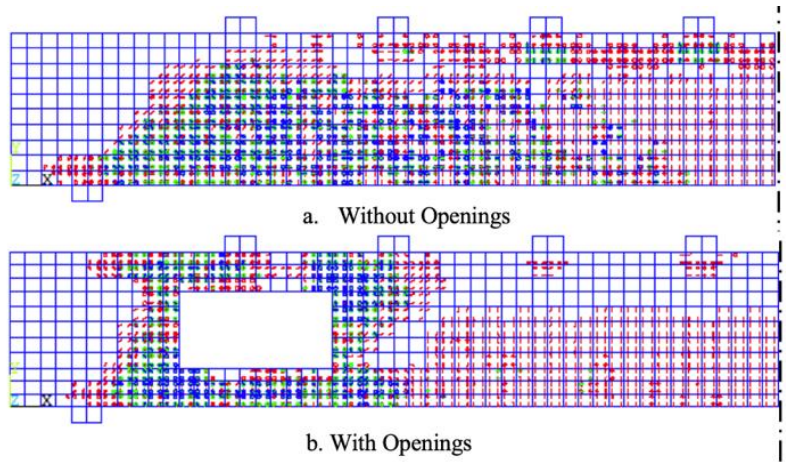

Fig. 5 Crack patterns for control beams

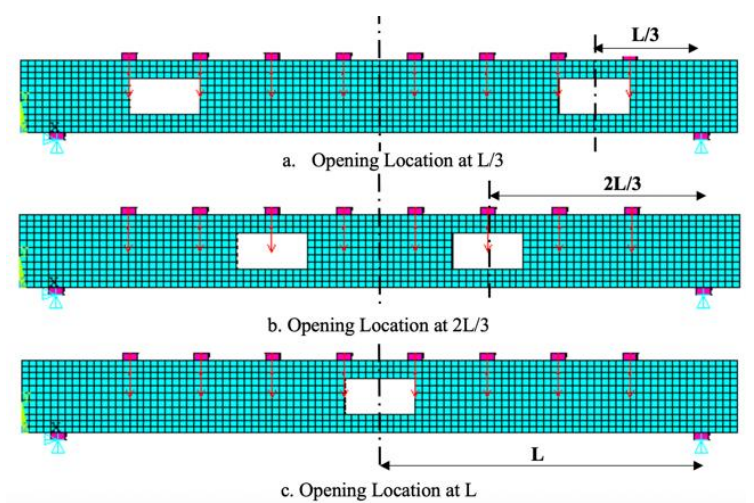

Fig. 4 Opening location

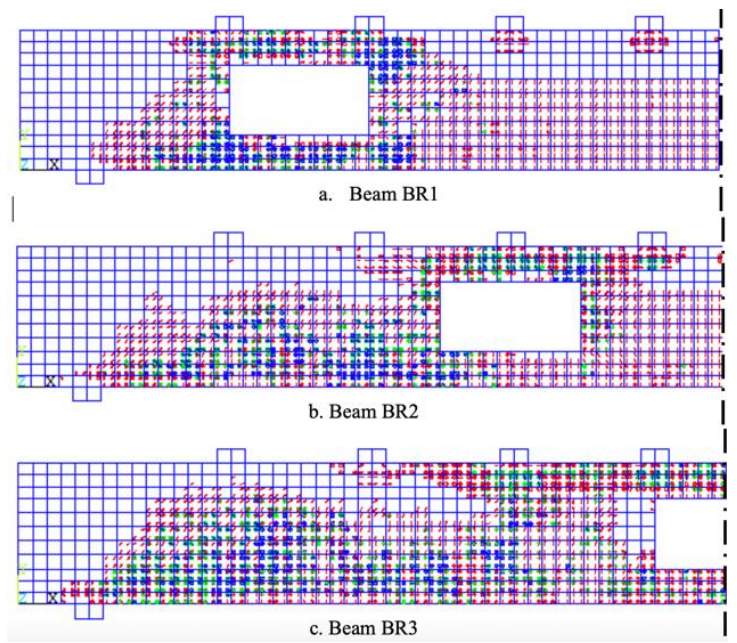

Fig. 6 Crack patterns for beams BR1, BR2, BR3 


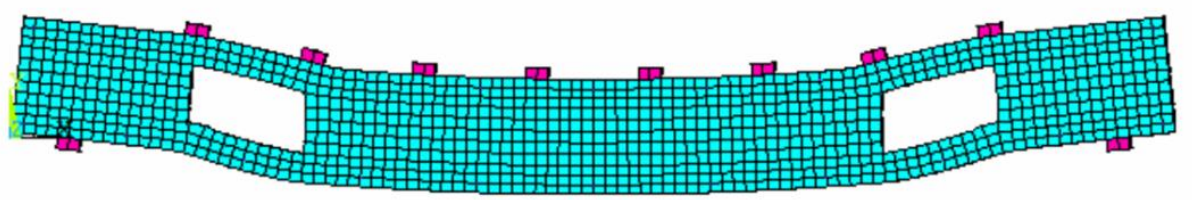

a. Beam BR1

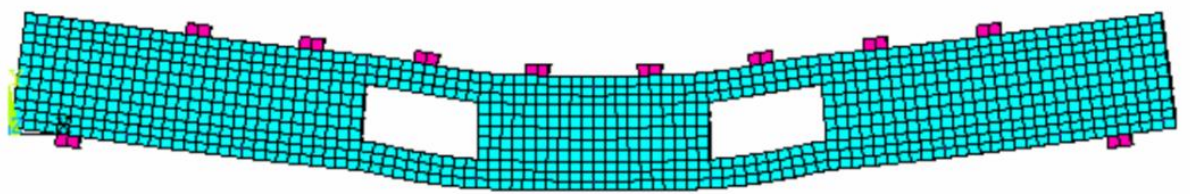

b. Beam BR2

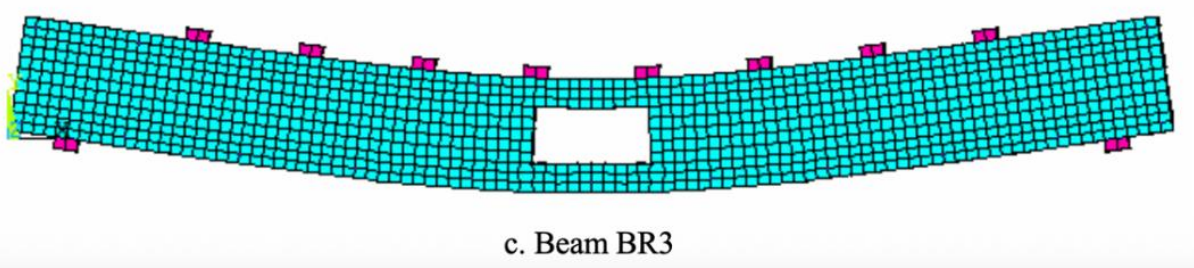

Fig. 7 Deformed shape for beams BR1, BR2, BR3

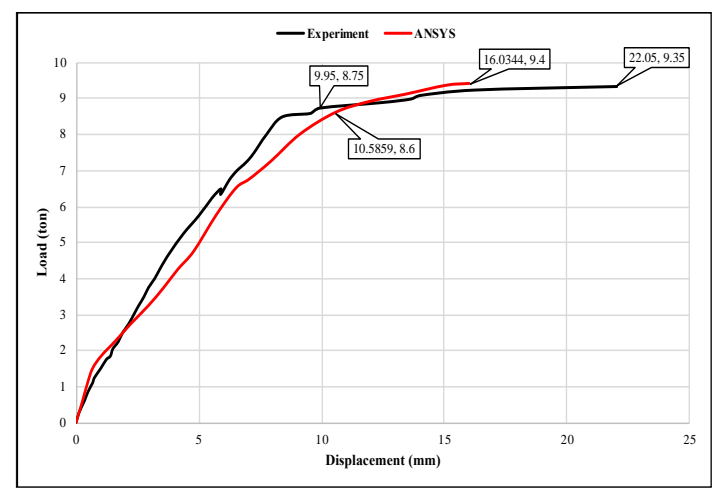

a. Experiment \& ANSYS beam (B)

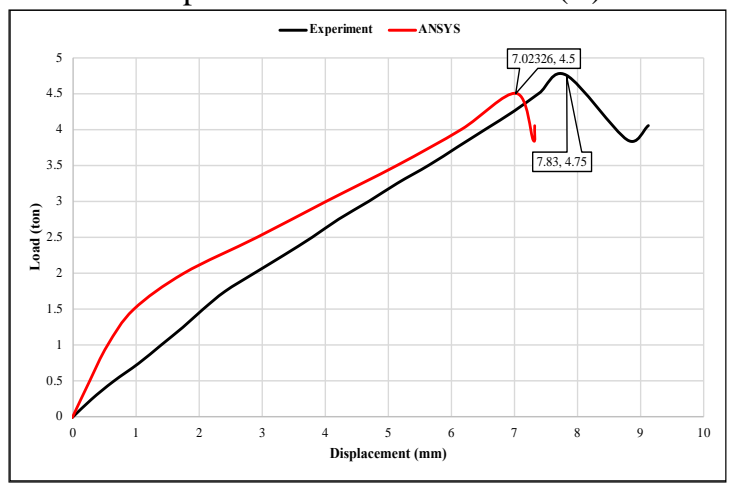

c. Experiment \& ANSYS beam (B7)

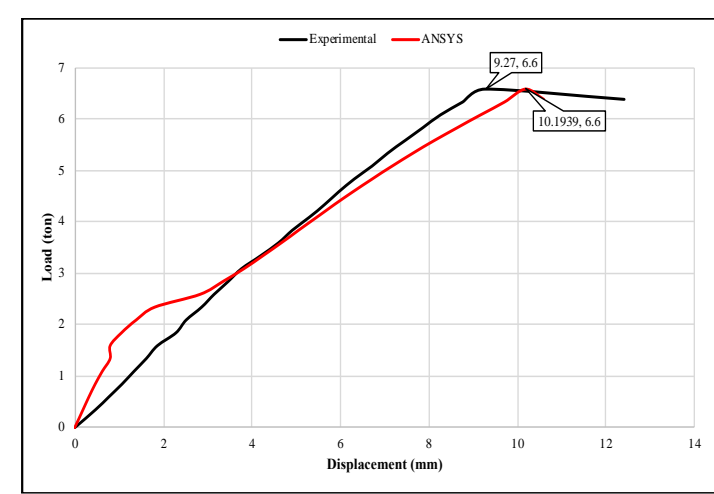

b. Experiment \& ANSYS beam (B1)

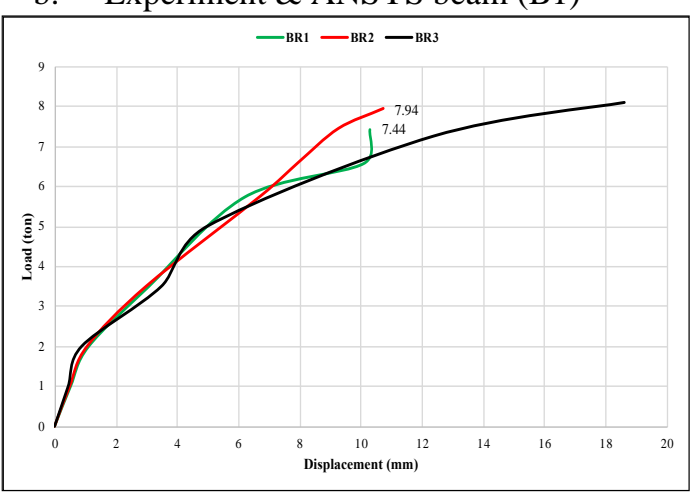

d. ANSYS beam (BR1, BR2, BR3) 


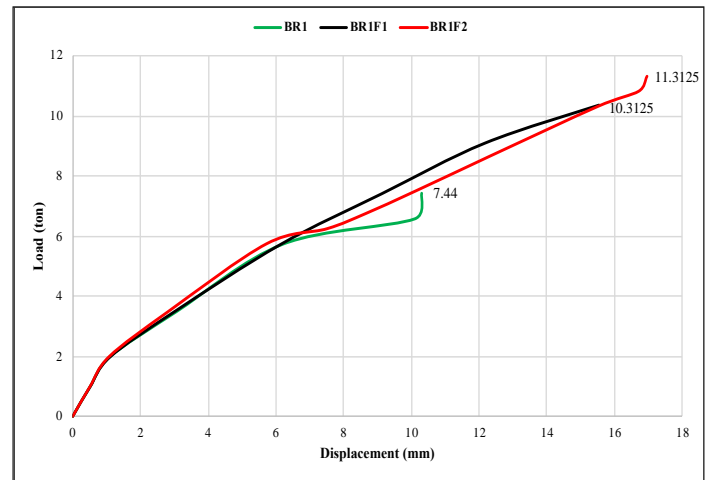

e. ANSYS beam (BR1, BR1F1, BR1F2)

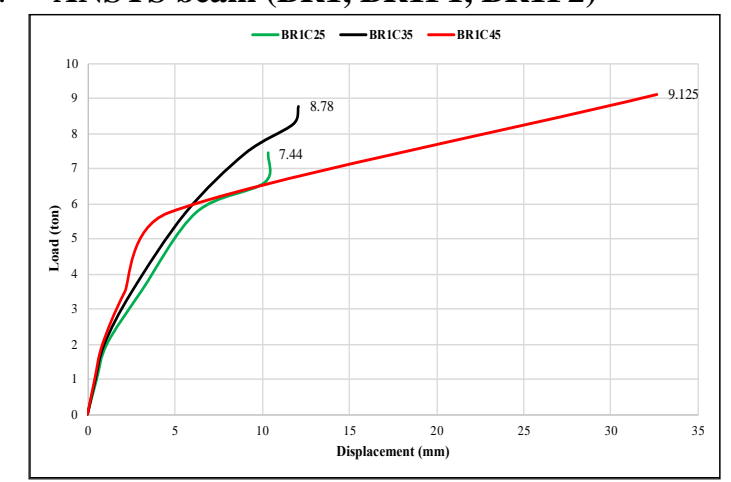

g. ANSYS beam (BR1C25, BR1C35,

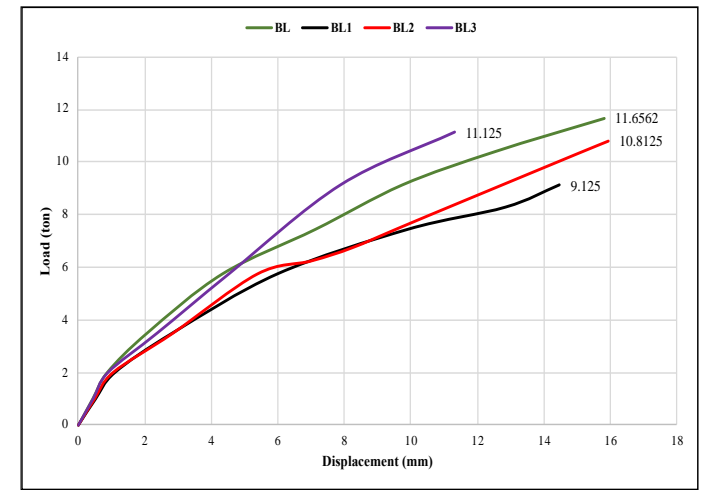

f. ANSYS beam (BL, BL1, BL2, BL3)

Fig. 8 P-Delta curves

\section{Conclusions}

This section summarizes the results of nonlinear finite analysis modeling of fifteen reinforced concrete beams with and without opening which were completed by using ANSYS version 15.0. The results were carefully investigated, and the following items were concluded:

1. The effect of opening distance from support edge had significant impact of the failure and displacement amount and location. Failure load is decreased around $47.67 \%$ due to creating opening in the shear span.

2. Using rectangular beam section during analysis or experimental study is given inaccurate results for beam capacity with and without opening. Failure load for $\mathrm{L}$ beam section without opening is increased by around $35.58 \%$ comparing with rectangular section. However, this concept is not applicable for beam with opening.

3. Increasing concrete compressive strength from 25 to $45 \mathrm{MPa}$ for beam with opening leading to increasing shear strength capacity around $23 \%$.

4. ANSYS version 15.0 is an effective tool to solve finite element problems. It is capable to simulate and analyze reinforced concrete beam with and without strengthening as a non-homogenous material with a non-linear response and gives acceptable results comparing with previous experimental study.

5. Increasing the number of strengthening layers CFRP will have insignificant improvement.

6. Using high concrete compressive strength will improve beam overall rigidity that can save the cost of required strengthening after casting. 


\section{Refences}

[1] T. M. Pham, H. Hao, "Behavior of fiber-reinforced polymer-strengthened reinforced concrete beams under static and impact loads". International Journal of Protective Structures, Volume 8 issue, March 2017.

[2] S. Amiri, R. Masoudnia, A. A. Pabarja, "The study of the effects of web openings on the concrete beams". Australian Journal of Basic and Applied Sciences, 5(7): 547-556, 2011.

[3] A. H. Ali, H. M. Mohamed, and B. Benmokrane, "Shear strength of circular concrete beams reinforced with glass fiber-reinforced polymer bars and spirals". ACI Structural Journal, Title no. 114-S04, January-February 2017.

[4] A. Hassan, A. E. Shoeib, and M. Abd El-Magied, "Use of carbon nanotubes in the retrofitting of reinforced concrete beams with an opening and the effect of direct fire on their behavior". International Journal of GEOMATE, April, 2018 , Vol.14, Issue 44, pp.149-158.

[5] V. F. Ibrahem. "Strengthening of R.C beams with opening created after casting using F.R.P”. Faculty of Engineering Helwan University M. Sc. Thesis.

[6] N. Z. Hassan, A. G. Sherif, A. H. Zamarawy, "Finite element analysis of reinforced concrete beams with opening strengthened using FRP”. Ain Shams Engineering Journal, 531-537, 2017.

[7] Y. Y. Qader Kawani , J. A. Saeed, M. O. Hasan, "Shear strength and behavior of reinforced concrete T-Beam with openings in both web and flange", Journal of Zankoy Sulaimani, 20 March 2017.

[8] Jainu P S, Rajalakshmi U, “Analytical study on shear behaviour of T beam with web opening”s, International Journal for Research in Applied Science \& Engineering Technology (IJRASET), Volume 7 Issue VI, June 2019.

[9] M. Zhu, Q. Jiang, H. Huang, C. Liang, “The experimental study on shear behavior of concrete I-shaped beam with web openings", 5th International Conference on Advanced Design and Manufacturing Engineering (ICADME), 2015.

[10] S. Yaohui, "Effect Analysis of Reinforced Concrete Beam with Opening Strengthened with Steel Sleeve", 2nd International Symposium on Advances in Electrical, Electronics and Computer Engineering (ISAEECE), 2017.

[11] A. A. Jaafer, A. W. Abdulghani, "Nonlinear finite element analysis for reinforced concrete haunched beams with opening". Materials Science and Engineering $454,2018$.

[12] A. A. H. Abdallah, "Methodology of bending of RC beams with opening for the usage in construction engineering management", Civil Engineering Research Journal ISSN: 2575-8950, 31 August 2017. 